\title{
Review \\ Jet lag: biology, sleep and coping strategies
}

\author{
Marasinghe $\mathbf{M}$ G C $\mathbf{P}^{1}$ \\ Journal of the Ceylon College of Physicians, 2014, 45, 39-41
}

Jet lag is a circadian rhythm disturbance caused by rapid travelling across multiple time zones. ${ }^{1}$ At the new destination the passenger faces circadian desynchrony by having new day-night timing with nonadapted internal body clock. Worldwide, the number of daily flights has passed the 100,000 mark in year $2014 .^{2}$ With this rapid rise of air travel, jet lag has become a common problem. It is important to understand basic sleep related concepts of jet lag, to minimize its consequences.

The sleep/wake pattern of the human body (internal body clock) is determined by the suprachiasmaticnucleus (SCN) of the hypothalamus. It is fine-tuned by external cues such as exposure to light, social interactions, timing of diet and exercise. ${ }^{3}$ The human internal body clock is adapted for a 24-hour sleep/ wake cycle according to the natural 24-hour day-night cycle. However, free running studies (done in an environment without light and other external factors) have shown that the human circadian cycle is slightly longer than 24 hours. ${ }^{4}$ With the arrival at a new place across the globe, the SCN changes its timing corresponding to the new environment settings. This gradual adaptation process is called re-entrainment. The passenger experiences jet lag during this period.

Time taken for re-entrainment is different for eastwards flying and westwards flying. ${ }^{5}$ Colombo to London flight is a westward flight and Colombo to Sydney is an eastward flight. Colombo is ahead of London time by five and half hours, where the clock needs setting to an early time when one reaches London. Hence, there is more time to complete that particular day and the SCN has to delay the onset of sleep. This is called phase delaying. Vice versa applies for eastward flying where the SCN does phase advancing. Phase delay is a quicker process than phase advancing. ${ }^{5}$ This is attributed to the fact that the human circadian cycle is slightly longer than 24 hours. It is a relatively easy process to adapt to a lengthened circadian cycle than to a shortening of the cycle. Studies have estimated that phase delay occurs at a rate of 1.5 hours a day and phase advance at a

\footnotetext{
${ }^{1}$ Consultant Physician and Senior Lecturer in Medicine, Faculty of Medical Sciences, University of Sri Jayewardenepura, Sri Lanka.
}

rate of an hour a day. ${ }^{6}$ Thus the duration of jet lag is shorter in westwards flying than eastwards flying. Furthermore, if there is a 9-hour time difference between the two travel places, phase delaying and phase advancing will be completed in six days and nine days respectively.

During sleep, maximum sleepiness occurs when the core body temperature is minimum ( $T$ min). $T$ min falls 4-6 hours before the wake up time. In a person who sleeps from $10 \mathrm{pm}$ to $6 \mathrm{am}$, it falls between 12 midnight to $2 \mathrm{am}$. Research has shown that it is difficult to initiate and maintain sleep 6 hours after T min and also to be awake closer to $\mathrm{T}$ min London time. ${ }^{7}$ When travelling, although it is night time at the new destination, it is challenging to initiate sleep if the $T$ min has passed by at least 6 hours. During the process of re-entrainment $\mathrm{T}$ min slowly shifts towards the new night time and when that is completed the sleep is synchronized. The traveler's sleeping pattern is irregular and incomplete until the re-entrainment process is completed. In addition, jet lag may cause short-term problems such as disturbed sleep, lack of concentration, poor performance at tasks/sports and daytime fatigue. ${ }^{8}$ Frequent air travelling causes longterm effects as well. Cardiovascular disease, ${ }^{9}$ diabetes mellitus $^{9}$ and cognitive deficits ${ }^{10}$ are commoner among them. Studies have shown an increased breast cancer risk among frequent air travelers due to regular circadian disturbances. ${ }^{11}$

Minimization of the short-term effects of jet lag is an imperative issue for many travelers worldwide. Presetting the internal body clock to new timing prior to travel or facilitating the re-entraining process has shown promising results. Following are some ways this can be achieved-

1. Exposure to timed bright light 2-3 days prior to travel helps to phase advance or phase delay the human biological clock. One such study conducted by Burgess and others successfully phase advanced the sleep schedule prior to eastward travel using light therapy. ${ }^{12}$ Timed natural light exposure at the new destination has also been shown to be helpful to counteract jet lag. ${ }^{13}$ Exposure to light in the morning hours of the day advances the sleep onset time and exposure in the afternoon delays the sleep. ${ }^{14}$ Hence, it is evident that the traveler should be exposed to morning 
light and should avoid afternoon light to advance sleep following eastward flying. Light boxes, light visors and head-mounted goggles can be used in winter months when there is no natural sunlight.

2. It is well established that Caffeine delays sleep if it is taken close to bedtime. On the other hand it enhances daytime alertness. Therefore cautious consumption of coffee is sensible inflight and during the first few days of arrival. ${ }^{15}$

3. Alcohol helps to initiate sleep, but nonetheless disturbs the second half of the sleep cycle. It is advisable to avoid alcohol during the jet lag period.

4. Exercise in the morning advances sleep. Hence, timing of exercise helps to change the sleep wake cycle faster.

5. Melatonin is a hormone secreted by the human pineal gland during the night. It promotes sleep. Timed administration of melatonin tablets help to phase shift the sleep wake cycle. Melatonin is available as $5 \mathrm{mg}$ tablets. If it is taken in the morning it delays sleep (phase delay) and if taken in the afternoon it advances sleep (phase advance). It is used as a novel therapy for circadian disturbances including jet lag. ${ }^{15,16}$ The lower physiological dose of $0.5 \mathrm{mg}$ of melatonin was almost as effective as the pharmacological dose of $5.0 \mathrm{mg} .^{17}$

6. Research has revealed mixed conclusions for the use of sleep promoting medications for jet lag. Benzodiazepine derivatives such as temazepam ${ }^{18}$ and midazolam ${ }^{19}$ help to improve the sleep duration, however they do not improve the other symptoms of jet lag. Non-benzodiazepine medications such as zolpidem also has been shown to improve the sleep duration but not improvement of other symptoms of jet lag. ${ }^{20}$ The use of sleep promoting agents for jet lag induced insomnia is a rational treatment and consistent with the standard recommendations for the treatment of short-term insomnia. ${ }^{21}$ On the other hand, the beneficial effects of these drugs on daytime symptoms of jet lag are yet to be established. ${ }^{21}$

7. Remaining asleep till the local bed time, is a popular strategy that most travellers try. However it is important to understand that the act of going to sleep itself contributes to a phase shift mostly by altering the activity levels and altering the exposure to light, rather than re-setting the internal body clock. Nonetheless there is data to suggest that sleep itself does have small phase shifting effects independent of exposure to light. ${ }^{22}$

8. For short term travellers who are staying less than a week such as businessmen, pilots and flight attendants, it is advisable not to take measures to change the original circadian settings since they are returning home before the re-entrainment process is completed.

To minimize the jet lag and to accelerate the reentrainment process it is important to consider the direction of the travel first i.e. east or west. After travelling east "phase advancing" and travelling west "phase delaying" will take place at SCN. Travellers can expedite phase delaying by exposure to afternoon sun light, engaging in afternoon exercise, consuming melatonin in the morning hours and the phase advancing can be expedited by exposure to morning sun light, engaging in morning exercise, consuming melatonin in the afternoon. Going to bed at local night time with or without sleep promoting medication will help both processes. Caffeine should not be consumed closer to sleeping time and alcohol needs to be avoided till the jet lag is over.

With the number of travellers undertaking long distance flights continuing to increase, jet lag $-\mathrm{a}$ troublesome short term circadian rhythm disturbance has become a common problem. This disorganization of the circadian system leads to a cluster of short term and long term consequences. The broadly accepted treatment strategies involving exposure to light, melatonin, sleep promoting medications and other non-medicinal cues have been shown to be effective when appropriately timed. Future research with an improved understanding of circadian disturbances in travelers will undoubtedly be beneficial in resolving the problems related to jet lag.

\section{References}

1. Sack R, Auckley D, Auger R, Carskadon M, Wright K, Vitiello M, et al. Circadian rhythm sleepdisorders: Part 1, basic principles, shift work and jet lag disorders. Sleep 2007; 30: 1460-83.

2. www.garfors.com/2014/06/100000-flights-day.

3. Brainard GC, Hanifin JP. Photons, clocks, and consciousness. J Biol Rhythms 2005; 20: 314-25.

4. Dijk DJ, Lockley SW. Integration of human sleep-wake regulation and circadian rhythmicity. J Appl Physiol 2002; 92: 852-62.

5. Aschoff J, Hoffmann K, Pohl H, Wever R. Re-entrainment of circadian rhythms after phase shifts of the zeitgeber. Chronobiologia 1975; 2: 23-78.

6. Burgess, HJ.; Eastman, Cl. Prevention of jet lag. Physicians' Information and Education Resource (PIER). Am College of Physicians, 2003. http://Pier.acponline.org.

7. Czeisler CA, Zimmerman JC, Ronda JM, Moore-Ede MC, Weitzman ED. Timing of REM sleep is coupled to the circadian rhythm of body temperature in man. Sleep 1980; 2(3), 329-46. 
8. Mary Choy, Rebecca L. Salbu. Jet Lag. Current and Potential Therapies 2011; 36(4): 221-24, 31.

9. Hampton SM, Morgan LM, Lawrence N, Anastasiadou T, Norris F, Deacon S, et al. Postprandial hormone and metabolic responses in simulated shift work. J Endocrinol 1996; 151: 259-67.

10. Cho K, Ennaceur A, Cole JC, Suh CK. Chronic jet lag produces cognitive deficits. J Neurosci 2000; 20:1-5.

11. Rafnsson V, Tulinius H, Jonasson JG, Hrafnkelsson J. Risk of breast cancer in female flight attendants: a populationbased study (Iceland). Cancer Causes Control 2001; 12: 95-101.

12. Burgess HJ, Crowley SJ, Gazda CJ, Fogg LF, Eastman Cl. Preflight adjustment to eastward travel: 3 days of advancing sleep with and without morning bright light. Journal of Biological Rhythms 2003;18: 318-28.

13. Boulos Z, Campbell SS, Lewy AJ, Terman M, Dijk DJ, Eastman Cl. Light treatment for sleep disorders: consensus report. VII. Jet lag. J Biol Rhythms 1995; 10: 167-76.

14. Czeisler C, Wright $\mathrm{K}$, Jr. Influence of light on circadian rhythmicity in humans. In: Turek F, et al., editors. In Regulation of Sleep and Circadian Rhythms. 1999. pp. 149-80.

15. Beaumont $\mathrm{M}$, Batejat $\mathrm{D}$, Pierard $\mathrm{C}$, et al. Caffeine or melatonin effects on sleep and sleepiness after rapid eastward transmeridian travel. Journal of Applied Physiology 2004; 96: 50-8.
16. Comperatore CA, Lieberman HR, Kirby AW, Adams B, Crowley JS. Melatonin efficacy in aviation missions requiring rapid deployment and night operations. Aviat Space Environ Med 1996; 67: 520-4.

17. Suhner A, Schlagenhauf $P$, Johnson R, Tschopp A, Steffen R. Comparative study to determine the optimal melatonin dosage form for the alleviation of jet lag. Chronobiol Int 1998;15: 655-66.

18. Reilly T, Atkinson G, Budgett R. Effect of low-dose temazepam on physiological variables and performance tests following a westerly flight across five time zones. International Journal of Sports Medicine 2001; 22: 166-74.

19. Lavie P. Effects of midazolam on sleep disturbances associated with westward and eastward flights: evidence for directional effects. Psychopharmacology (Berl) 1990; 101: 250-4.

20. Jamieson AO, Zammit GK, Rosenberg RS, Davis JR, Walsh JK. Zolpidem reduces the sleep disturbance of jet lag. Sleep Medicine 2001; 2: 423-30.

21. Robert L Sack, Dennis Auckley, R. Robert Auger, Mary A. Carskadon, Kenneth P. Wright, Jr, Michael V. Vitiello, Irina V. Zhdanova. Circadian Rhythm Sleep Disorders: Part I, Basic Principles, Shift Work and Jet Lag Disorders. An American Academy of Sleep Medicine Review. Sleep 2007; 30(11): 1460-83.

22. Mistlberger RE, Skene DJ. Nonphotic entrainment in humans? J Biol Rhythms 2005; 20: 339-52. 